\title{
Expression of the TPa and TPB isoforms of the thromboxane prostanoid receptor (TP) in prostate cancer: clinical significance and diagnostic potential
}

\author{
Eamon P. Mulvaney ${ }^{1}$, Christine Shilling ${ }^{3}$, Sarah B. Eivers ${ }^{1}$, Antoinette S. Perry ${ }^{1}$, \\ Anders Bjartell ${ }^{4}$, Elaine W. Kay ${ }^{3}$, R. William Watson ${ }^{2}$, B. Therese Kinsella ${ }^{1}$ \\ ${ }^{1}$ UCD School of Biomolecular and Biomedical Science, University College Dublin, Belfield, Dublin, Ireland \\ ${ }^{2}$ UCD School of Medicine, UCD Conway Institute of Biomolecular and Biomedical Research, University College Dublin, Belfield, \\ Dublin, Ireland \\ ${ }^{3}$ Department of Pathology, Beaumont Hospital and Royal College of Surgeons, Dublin, Ireland \\ ${ }^{4}$ Department of Translational Medicine, Division of Urological Cancers, Skåne University Hospital Malmö, Lund University, \\ Sweden
}

Correspondence to: B. Therese Kinsella, email: therese.kinsella@ucd.ie

Keywords: thromboxane, receptor, prostate, cancer, prostanoid

Received: June 09, $2016 \quad$ Accepted: September 19, $2016 \quad$ Published: September 26, 2016

\section{ABSTRACT}

The prostanoid thromboxane (TX)A $\mathrm{A}_{2}$ plays a central role in haemostasis and is increasingly implicated in cancer progression. TXA ${ }_{2}$ signals through two T Prostanoid receptor (TP) isoforms termed TPa and TP $\beta$, with both encoded by the TBXA2R gene. Despite exhibiting several functional and regulatory differences, the role of the individual TP isoforms in neoplastic diseases is largely unknown.

This study evaluated expression of the TPa and TP $\beta$ isoforms in tumour microarrays of the benign prostate and different pathological (Gleason) grades of prostate cancer (PCa). Expression of TP $\beta$ was significantly increased in PCa relative to benign tissue and strongly correlated with increasing Gleason grade. Furthermore, higher TP $\beta$ expression was associated with increased risk of biochemical recurrence (BCR) and significantly shorter disease-free survival time in patients post-surgery. While TPa was more variably expressed than TPB in PCa, increased/high TPa expression within the tumour also trended toward increased BCR and shorter diseasefree survival time. Comparative genomic CpG DNA methylation analysis revealed substantial differences in the extent of methylation of the promoter regions of the $T B X A 2 R$ that specifically regulate expression of TPa and TP $\beta$, respectively, both in benign prostate and in clinically-derived tissue representative of precursor lesions and progressive stages of PCa. Collectively, TPa and TP $\beta$ expression is differentially regulated both in the benign and tumourigenic prostate, and coincides with clinical pathology and altered CPG methylation of the TBXA2R gene. Analysis of TP $\beta$, or a combination of TPa/TP $\beta$, expression levels may have significant clinical potential as a diagnostic biomarker and predictor of PCa disease recurrence.

\section{INTRODUCTION}

As one of the most common cancers among men, prostate cancer $(\mathrm{PCa})$ is a leading cause of death within this population across the developed world [1]. From the clinical standpoint, the vast majority of prostate tumours remain asymptomatic, and in most cases an active surveillance approach is followed [1, 2]. Treatments for what are deemed as the more significant or progressive cases include surgery, radiation therapy, anti-androgen therapies and chemotherapy [1]. However, following surgery or radiation therapy, approximately one third of patients with localised PCa experience disease relapse, typically detected by a rise in serum prostate-specific antigen (PSA) levels, termed "biochemical recurrence (BCR)" or PSA failure [3]. Furthermore, despite the initial success of androgendeprivation therapies (ADTs), many patients eventually fail in this and the disease develops to the incurable metastatic 
castrate-resistant PCa (CRPC) stage, for which only palliative treatments are typically advised [4]. Hence, a key goal of current research is to understand the mechanistic basis of the disease and to identify biomarkers that will discriminate between the indolent conditions and the more aggressive or fatal forms of $\mathrm{PCa}$, allowing clinicians and patients to make more informed decisions on the optimal treatment approaches [2].

By now numerous epidemiological studies have shown that regular intake of the non-steroidal antiinflammatory drug (NSAID) aspirin, an inhibitor of the cyclooxygenases (COXs), substantially reduces risks in both the incidence and progression of several prevalent cancers, including $\mathrm{PCa}$ [5-7]. While those studies do not specify which COX-1/2 metabolite(s) are actually lowered by aspirin accounting for its prophylactic benefits, recent studies suggest that some/much of its anti-cancer effects may be due to its ability to inhibit thromboxane (TX) $\mathrm{A}_{2}$ generation, a prostanoid more typically implicated in thrombosis and cardiovascular disease. Increased levels of $\mathrm{TXA}_{2}$ and expression of its synthase and its $\mathrm{T}$ prostanoid receptor, the TP, have been found in a number of prevalent cancers [8] and, mechanistically, the role of $\mathrm{TXA}_{2}$ in cancer may be explained by the ability of the $\mathrm{TXA}_{2}$-TP axis to regulate key mitogenic/extracellular signal regulated kinase (ERK)- and RhoA-mediated signalling cascades that contribute to tumour development and metastasis [9, 10]. For example, increased levels of $\mathrm{TXA}_{2}, \mathrm{TXA}_{2}$ synthase and the TP strongly correlate with bladder [11], prostate [12, 13], colorectal [14, 15] and nonsmall cell lung cancer [16]. Furthermore, it has long been known that platelets, the main source of $\mathrm{TXA}_{2}$ and key target of aspirin, play a central role in tumour progression promoting cancer cell metastasis, immune evasion and extravasation [17].

In humans, TXA 2 actually signals through two isoforms of the TP, termed TP $\alpha$ and TP $\beta$, which have both overlapping but also distinct physiological roles, exhibiting several critical differences in their modes of signalling and regulation $[10,18-23]$. While TP $\alpha$ and TP $\beta$ are encoded by the same $T B X A 2 R$ gene, they are differentially expressed in a range of tissues due to their transcriptional regulation by different Promoters, designated Prm1 and Prm3, respectively, within the $T B X A 2 R$ [24-27]. Functionally, both TP $\alpha$ and TP $\beta$ couple to $\mathrm{G} \alpha_{\mathrm{q}}$-mediated phospholipase $(\mathrm{PL}) \mathrm{C} \beta$ activation, their primary effector, but also readily couple to activation of the ERK and $\mathrm{G} \alpha_{12}$-RhoA-signalling cascades promoting cell proliferation, mitogenesis, and the dynamic changes that drive cell migration and metastasis $[18,28]$. In more recent studies, it was also discovered that both TP $\alpha$ and TP $\beta$ directly interact with and regulate signalling by protein kinase C-related kinase/ protein kinase novel (PRK/PKN) [19], a family of 3 AGC kinases and RhoA effectors that act immediately downstream of phosphatidyl inositol (Pi) 3 'kinases and strongly, yet differentially, implicated in several cancers
[29-31]. Indeed, in the specific context of PCa, activation of the PRKs (e.g. PRK1) in response to androgen receptor (AR) signalling catalyses phosphorylation of histone $(\mathrm{H}) 3$ at Thr11 (H3pThr11) which, in-turn, serves as a specific epigenetic marker and gatekeeper of androgen inducedchromatin remodelling and-gene expression within the prostate [19, 32-34]. Furthermore, similar to the AR, TP-mediated PRK1 activation not only leads to H3Thr11 phosphorylation in response to $\mathrm{TXA}_{2}$ but can also cooperate with the AR to enhance androgen induced -chromatin remodelling (H3pThr11) and -transcriptional activation/ gene expression within the prostate [19]. Hence, similar to the androgens, these studies suggested that TXA ${ }_{2}$, through its ability to directly regulate PRK-induced $\mathrm{H} 3 \mathrm{pThr} 11$, is a strong epigenetic regulator thereby adding to the range of possible mechanisms whereby the aspirin-target TXA may influence neoplastic growth. Added to this complexity, the TP $\alpha$ and TP $\beta$ isoforms appear to differentially associate with- and regulate-signalling by the individual PRKs (PRK1/PKN $\alpha$, PRK2/PKN $\gamma$, PRK3/PKN $\beta$ ), suggesting clear functional differences between TP $\alpha$ and TP $\beta$ within the prostate and, potentially, in PCa [35].

As stated, while a number of studies have reported linkages between increased $\mathrm{TXA}_{2}$ signalling and $\mathrm{TP}$ expression with certain neoplasms [9-15], to date such studies have not investigated the role of the individual TP $\alpha$ and TP $\beta$ isoforms in those diseases. Hence, in view of the clear functional and regulatory differences between TP $\alpha$ and TP $\beta$, coupled with the discovery of their ability to regulate the PRK-signalling cascade implicated in PCa etiology, and in a TP isoform-specific manner, the aim of this study was to histologically evaluate expression of the individual TP $\alpha$ and TP $\beta$ isoforms in clinical prostatectomy specimens representative of the benign prostate and of different pathological (Gleason) grades of PCa. Furthermore, it was aimed to investigate whether $\mathrm{TP} \alpha$ and/ or TP $\beta$ expression might serve as surrogate biomarker(s) in $\mathrm{PCa}$, correlating with Gleason grade, pathologic tumour staging (PTS) or with significant clinical outcomes, such as patient progression to $\mathrm{BCR}$, potential for disease relapse and/or the development of the more severe aggressive forms of $\mathrm{PCa}$.

\section{RESULTS}

\section{Expression of TP $\alpha$ and TP $\beta$ in benign prostate and prostate tumour tissue}

Expression of the individual TP $\alpha$ and TP $\beta$ isoforms was initially evaluated through IHC analysis in a series of full-face radical prostatectomy specimens $(N=17)$ using affinity-purified anti-TP $\alpha$ or anti-TP $\beta$ isoform-specific antibodies [10,36]. Validation of antibody specificity was confirmed whereby pre-incubation of the anti-TP $\alpha$ antiserum with the cognate TP $\alpha$, but not with the TP $\beta$, antigenic peptide blocked all anti-TP $\alpha$ IHC staining while 
pre-incubation of the anti-TP $\beta$ antiserum with the cognate TP $\beta$, but not with the TP $\alpha$, antigenic peptide competed all anti-TP $\beta$ staining (Supplementary Figure S1A). Validation of the TP isoform-specific antibodies was also demonstrated whereby the individual anti-TPa and anti-TP $\beta$ antibodies specifically and exclusively immunoprecipitated only their cognate receptor isoform from HEK 293 cell lines expressing TP $\alpha$ or TP $\beta$ (Supplementary Figure S1B).

In all prostatectomy specimens, both $\mathrm{TP} \alpha$ and $\mathrm{TP} \beta$ were expressed in the fibromuscular stroma, consistent with the contractile role of TXA $\mathrm{T}_{2}$ in the prostate, and also in the luminal epithelial cells lining the secretory ducts (Figure 1A and Supplementary Figure S1C). In the benign tissue, expression of TP $\alpha$ was more predominant than TP $\beta$ in the stromal or smooth muscle regions (Figure 1A(i)) while, conversely, expression of TP $\beta$ was typically stronger than that of TP $\alpha$ within the glandular epithelium (Figure 1A(ii)). While expression of both TPa and TP $\beta$ was predominantly cytoplasmic (Figure 1A), nuclear staining of TP $\beta$, and to a much lesser extent of $\mathrm{TP} \alpha$, was also observed within the glandular epithelial cells in certain specimens (Figure 1A and Supplementary Figure S1C). Within the tumour epithelium, TP $\beta$ was again more strongly expressed than $\mathrm{TP} \alpha$, and there was a tendency toward increased expression of TP $\beta$, and to a lesser extent TP $\alpha$, in the tumour relative to the benign epithelium in sections from the same patient (Figure 1B and Supplementary Figure S1C). In the stromal regions of the prostate tissue, no substantial differences in either the cytoplasmic or nuclear expression of TP $\alpha$ or TP $\beta$ were evident between the benign and tumour regions.

\section{Correlation of TP $\alpha$ and TP $\beta$ expression with gleason grading}

The Gleason grade is the most common pathologic grading system for $\mathrm{PCa}$, and remains one of the most useful prognostic tools in assessing disease severity, risk of clinical recurrence, and often informs the specific treatment regime to be followed [37]. Bearing in mind the mounting evidence for the role of the $\mathrm{TXA}_{2}-\mathrm{TP}$ axis in cancer progression but also of the clear functional and regulatory differences between the TP $\alpha$ and TP $\beta$ isoforms $[10,18-23]$, it was deemed imperative to investigate expression of the individual TP $\alpha$ and TP $\beta$ isoforms in PCa and to establish whether cytoplasmic expression of either isoform within the glandular epithelium might correlate with Gleason grade.

Initially expression of TP $\alpha$ and TP $\beta$ was evaluated using IHC in the "PCRC TMA" patient cohort and, in each case, mean expression levels of both TP $\alpha$ and TP $\beta$ differed substantially in the $\mathrm{PCa}$ relative to the benign tissue (Figure 2). Specifically, in the case of $\operatorname{TP} \alpha$, alteration in its expression levels between the benign/BPH versus Gleason grade was variable, whereby some patients showed either no change, while others showed an increase and others an actual decrease in TP $\alpha$ expression in benign versus PCa epithelium. Hence, due to this variability, the only notable quantifiable difference in $\mathrm{TP} \alpha$ expression across the "PCRC TMA" was a modest but significant increase between the benign versus all Gleason groupings (Benign/ $\mathrm{BPH}$ versus Gleason 3/4/5; $P=0.024$; Figure 2A). Furthermore, while two-way contingency analyses (Fisher exact) showed that there was no significant difference in $\mathrm{TP} \alpha$ expression between benign/BPH and a combined Gleason $3 / 4 / 5$ cohort, there was a marginal, but significant nett decrease noted between benign/BPH and Gleason 3 groupings $(P=0.0458$; Table $1 \mathrm{~A})$. In the case of TP $\beta$, its expression in the epithelium was significantly increased between benign/BPH versus Gleason 3, Gleason 4, Gleason 5 ( $P<0.001$, all; Figure 2B). In addition, there was a significant increase in TP $\beta$ expression between the Gleason 3 versus Gleason 5 groupings $(P=0.003$; Figure 2B). Furthermore, contingency analysis showed that there was a highly significant increase in TP $\beta$ expression between benign/BPH versus Gleason 3/4/5, Gleason 3 alone, and also Gleason 4/5 $(P<0.0001$, all; Table 1B). There was also a significant increase in TP $\beta$ expression between the benign/BPH/Gleason 3 versus Gleason $4 / 5$ groupings $(P<0.0001$; Table 1B). While nuclear staining of TP $\beta$, and to a much lesser extent of $\mathrm{TP} \alpha$, was also observed within the glandular epithelium in certain TMA cores, this was not a consistent feature and did not correlate with Gleason grade in either case (Data not shown).

\section{Correlation of TP $\alpha$ and TP $\beta$ expression with disease-free survival}

While data from the "PCRC TMA" showed differential associations between TP $\alpha$ and TP $\beta$ expression and pathological $\mathrm{PCa}$ Gleason grading, it was of interest to determine if there is a correlation between TP $\alpha / \mathrm{TP} \beta$ expression and patient outcome following surgery and, hence, establish whether TP $\alpha$ or TP $\beta$ expression might have a prognostic or even therapeutic value in the clinical setting. Hence, expression of TP $\alpha$ and TP $\beta$ was further validated in the "Malmö TMA", a large patient cohort TMA for which 10-yr clinical follow-up history and pathological staging (PTS) data was also available. As previous, TP $\alpha$ and TP $\beta$ expression in the "Malmö TMA" was initially evaluated for correlation between benign/ $\mathrm{BPH}$ versus tumour tissue (Table 2A). Consistent with findings from the "PCRC TMA", contingency analysis showed that expression of TP $\beta$ in the "Malmö TMA" was significantly increased in the $\mathrm{PCa}$ relative to the benign tissue $(P<0.0001$; Table 2A). However, expression levels of TP $\alpha$ were more variable and in fact, across the "Malmö TMA", there was a nett decrease rather than increase in TP $\alpha$ expression in PCa tissue relative to the benign/BPH tissue $(P<0.0001$; Table $2 \mathrm{~A})$. Notably, these 
changes in TP $\alpha$ and TP $\beta$ expression also both correlated with Gleason score, wherein $\mathrm{TP} \alpha$ staining intensity was found to be decreased, and that of TP $\beta$ to be increased, across increasing Gleason score within the patient cohort relative to the benign tissue (Supplementary Figure S2A and S2B and Supplementary Table S1A and S1B). Changes in TP $\alpha$ and TP $\beta$ expression within this cohort were also correlated with pathological staging, wherein $\mathrm{TP} \alpha$ staining intensity was found to be unchanged but that of TP $\beta$ to be significantly increased between the organconfined pT2 and the invasive extraprostatic pT3 staging (Supplementary Figure 2C and 2D and Supplementary Table S1C).

At the time of reporting this study, approximately $30 \%$ of the Malmö patient cohort had progressed to BCR, defined as having a repeated serum PSA measurement of $>0.2 \mathrm{ng} / \mathrm{ml}$. To determine whether $\mathrm{TP} \alpha$ and/or TP $\beta$ expression levels may be a predictor of patient progression to $\mathrm{BCR}$, the correlation of the $\mathrm{BCR}$ status (Positive/Negative) with low/high levels of TP $\alpha$ and TP $\beta$ expression within the tumour cores was next analysed (Table 2B). High expression of TP $\beta$ within the tumour cores correlated significantly with a positive BCR status $(P=0.0045$; Table 2B). However, for TP $\alpha$, as stated while its expression was more variable across the TMA, in those patient cases where its expression was actually increased in the tumour relative to the benign/BPH tissue there was a trend, albeit not significantly, toward a positive correlation between high TP $\alpha$ expression in tumour cores of patients that were BCR positive ( $P=0.057$; Table $2 \mathrm{~B})$.

To determine whether TP $\alpha$ or TP $\beta$ expression level(s) is a significant predictor of BCR-free survival time following on from surgery, Kaplan-Meier survival curves were used to examine the relationship between low or high TP $\alpha$ or TP $\beta$ expression levels and diseasefree/BCR-free time using the "Malmö TMA" (Figure 3). Through this Kaplan-Meier analyses, for $\mathrm{TP} \alpha$, while not reaching statistical significance $(P=0.0776)$, a trend was observed wherein patient cases showing high $\mathrm{TP} \alpha$ expression were associated with a faster progression to BCR, in particular at 48-72 months' post-surgery (Figure 3A). Consistent with this trend, use of an ordinal scoring approach, as opposed to the binary low/high scoring approach, showed that increasing expression of $\mathrm{TP} \alpha$ significantly associates with a faster progression to BCR $(P=0.0291$; Supplementary Figure S3A). For TP $\beta$, its expression strongly correlated with time-to-progression to BCR, wherein patients with high TP $\beta$ expression in the tumour had significantly shorter BCR-free time after surgery compared to patients with low TP $\beta$ expression

\section{A Benign/BPH Tissue}
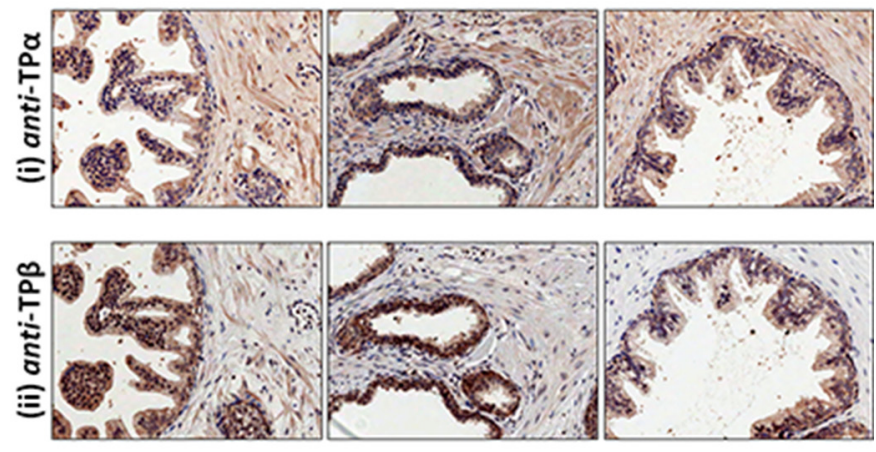

\section{B PCa Tumour Tissue}
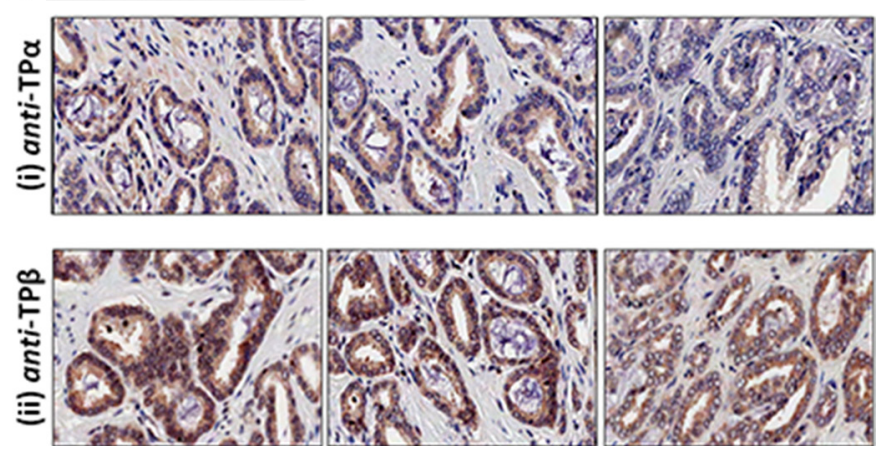

Figure 1: Expression of TP $\alpha$ and TP $\boldsymbol{\beta}$ in benign prostate and PC $\alpha$ tissue. Representative IHC analysis of TP $\alpha$ and TP $\beta$ protein expression in serial sections of paraffin-embedded, formalin-fixed full-face prostate tissues screened with affinity-purified anti-TP $\alpha$ or anti-TP $\beta$ antibodies. In all, 17 full-face sections were examined. Expression of TP $\alpha$ and TP $\beta$ was evident in the prostate glandular luminal epithelial cells and in the fibromuscular stromal smooth muscle cells where expression of both TP $\alpha$ and TP $\beta$ was predominantly cytoplasmic. In certain cases, nuclear expression of TP $\beta$ was also observed in the luminal epithelial cells. Panel (A) Benign prostate. Panel (B) Prostate tumour. All sections were counterstained with haematoxylin and images shown were captured at $200 \times$ magnification. 
(Figure 3B; $P=0.0032$ ). This finding was noticeable from very early stages post-surgery and the survival divergence worsened significantly from approximately 40 months' post-surgery (Figure 3B). These findings for TP $\beta$ were also observed using the ordinal scoring approach $(P=$ 0.0308; Supplementary Figure S3B).

To investigate whether expression levels of TP $\alpha$ and/or TP $\beta$ may add independent prognostic value over (i) Gleason scoring (GS) and (ii) pathological tumour staging (PTS) in the prediction of BCR-free survival time following surgery, additional multivariate time-to-event analyses were carried out (Supplementary Figure S4 and Supplementary Figure S5). As expected, GS strongly correlated with time-to-progression to $\mathrm{BCR}$, wherein cases with increasing GS had progressively shorter BCRfree time (Supplementary Figure S4A; $P<0.0001$ ). For $\mathrm{TP} \alpha$, multivariate analyses demonstrated a trend wherein increased or high TP $\alpha$ expression is associated with a shorter BCR-free time within certain GS groupings, in particular GS 5 cases (Supplementary Figure S4B; GS 5 , $P=0.0272, n=21 ;$ GS 6, $P=0.2003, n=74$; GS 7, $P=0.7201, n=101$; GS 9, $P=0.6254, n=13)$. For TP $\beta$, multivariate analyses demonstrated that its expression is also associated with a shorter BCR-free time within certain GS groupings, in particular GS 7 cases (Supplementary Figure 4C; GS 5, $P=0.0736, n=20$; GS 6, $P=0.6753$, $n=75$; GS 7, $P=0.0398, n=106$; GS 9, $P=0.3865$, $n=15$ ). In these analyses, the GS 8 and GS 10 datasets were excluded due to low numbers, precluding statistical analysis (GS 8, $n=3$; GS $10, n=1$ for both TP $\alpha$ and TP $\beta$ ). However, it is noteworthy that all these GS 8 and GS 10 cases showed high TP $\alpha$ and high TP $\beta$ expression and all rapidly progressed to BCR within five years. In the case of the second multivariate analysis (ii), as

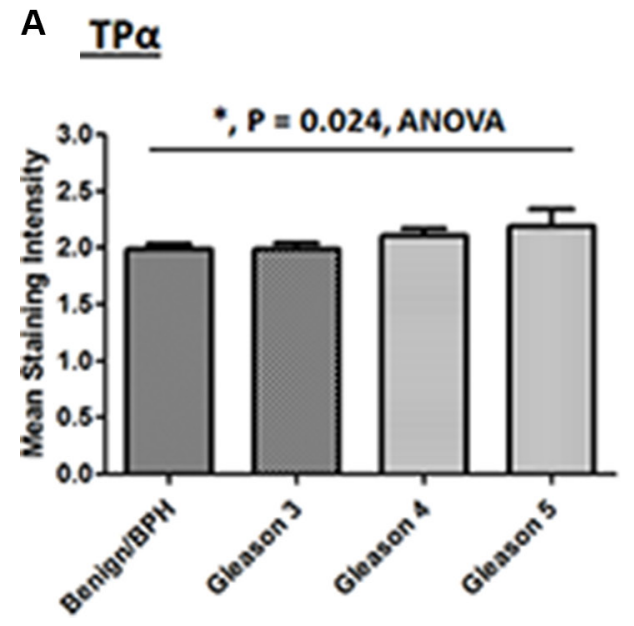

expected PTS strongly correlated with time-to-progression to BCR wherein cases with invasive pT3 staging had a significantly shorter BCR-free time compared to cases with organ-confined pT2 staging (Supplementary Figure S5A; $P<0.0001)$. In the case of TP $\alpha$, this multivariate analysis showed that high TP $\alpha$ expression is associated with a significantly shorter BCR-free time in cases with organ-confined pT2 staging (Supplementary Figure S5B; $P$ $=0.0007, n=105)$, but not in extra-prostatic/invasive pT3 cases (Supplementary Figure S5B; $P=0.8798, n=104$ ). In contrast, for TP $\beta$, multivariate analysis showed that high TP $\beta$ expression is associated with a significantly shorter BCR-free time in cases with invasive $\mathrm{pT} 3$ staging (Supplementary Figure S5C; $P=0.0293, n=107$ ), but not in organ-confined pT2 cases (Supplementary Figure S5C; $P=0.8229, n=109)$. Hence, these additional multivariate analyses suggest that expression of TP $\alpha$ and of TP $\beta$ may indeed provide independent prognostic value over and above that provided solely through histological Gleason scoring or pathological tumour staging.

\section{Analysis of the methylation profile of the promoter regions of the TBXA2R gene in benign prostate and PCa tissue}

CpG genomic DNA methylation through either hypermethylation or hypomethylation, particularly within the regulatory promoter elements, acts to regulate gene expression and plays a major role in cancer development through transcriptional silencing or activation of critical tumour suppressor genes or oncogenes, respectively [38]. Bearing in mind findings herein from two independent TMAs that expression of TP $\alpha$ and TP $\beta$ isoforms are significantly but differentially altered as a function of

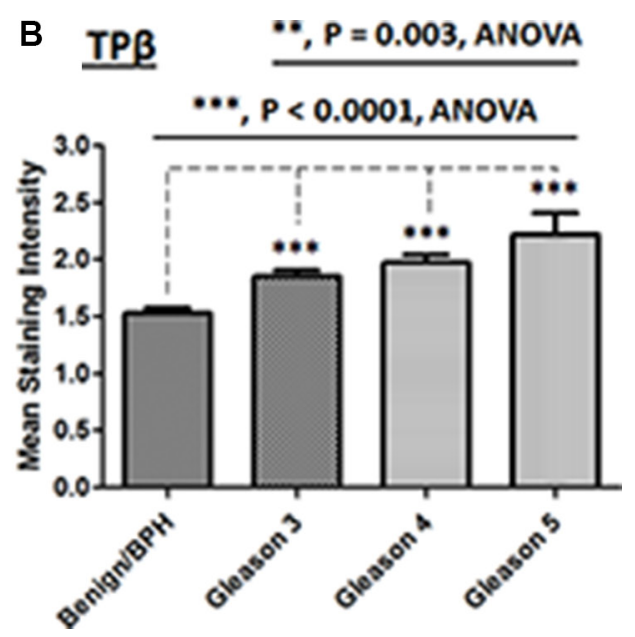

Figure 2: Correlation of TP $\alpha$ and TP $\beta$ staining intensity with Gleason grading in the PCRC TMA. Comparison of TP $\alpha$ (Panel A) and TP $\beta$ (Panel B) immunohistochemical staining intensities in the "PCRC TMA", where data is presented as the mean TP $\alpha$ or TP $\beta$ score (Range, $0-3$ ) for each particular histology present ( \pm SEM). Differences were analysed by one-way ANOVA group comparisons (solid black line) with individual post-hoc Bonferroni's Multiple Comparison Tests (dotted line) and the asterisks indicate where scoring of TP $\alpha($ Panel $A$ ) or TP $\beta$ (Panel B) staining intensity within the PCa tissue is significantly altered between the groups indicated, or compared to the Benign/BPH tissue, where *,** and $* * *$ indicate $P<0.05,0.01$ and 0.001 , respectively. 
Table 1A: "PCRC TMA" - TP $\alpha$ staining intensity/gleason grading correlation

\begin{tabular}{|c|c|c|c|c|}
\hline \multirow[t]{2}{*}{ Contingency Test } & \multirow[t]{2}{*}{ Histology } & $\begin{array}{c}\text { Low } \\
\text { Expression }\end{array}$ & $\begin{array}{c}\text { High } \\
\text { Expression }\end{array}$ & \multirow[t]{2}{*}{$P$ Value ${ }^{s}$} \\
\hline & & No. (\%) & No. (\%) & \\
\hline \multirow{2}{*}{ Histologically benign versus tumour (G3, G4 or G5) } & Benign/BPH $\left(n^{\#}=378\right)$ & $79(21)$ & $299(79)$ & \multirow{2}{*}{$P=0.1870$} \\
\hline & Gleason $3+4+5(n=604)$ & $149(25)$ & $455(75)$ & \\
\hline \multirow{2}{*}{ Histologically benign versus Gleason grade 3} & Benign/BPH $(n=378)$ & $79(21)$ & $299(79)$ & \multirow{2}{*}{$* P=0.0458$} \\
\hline & Gleason $3(n=299)$ & $83(28)$ & $216(72)$ & \\
\hline \multirow{2}{*}{$\begin{array}{l}\text { Histologically benign versus high grade tumour (G4 or } \\
\text { G5) }\end{array}$} & Benign/BPH $(n=378)$ & $79(21)$ & $299(79)$ & \multirow{2}{*}{$P=0.8509$} \\
\hline & Gleason $4+5(n=305)$ & $66(22)$ & $239(78)$ & \\
\hline \multirow{2}{*}{ Benign \& Gleason 3 versus high grade tumour (G4 or G5) } & Benign/BPH+Gleason $3(n=677)$ & $162(24)$ & $515(76)$ & \multirow{2}{*}{$P=0.4628$} \\
\hline & Gleason $4+5(n=305)$ & $66(22)$ & $239(78)$ & \\
\hline
\end{tabular}

Table 1B: "PCRC TMA" - TPß staining intensity/gleason grading correlation

\begin{tabular}{|c|c|c|c|c|}
\hline \multirow[t]{2}{*}{ Contingency Test } & \multirow[t]{2}{*}{ Histology } & $\begin{array}{c}\text { Low } \\
\text { Expression }\end{array}$ & $\begin{array}{c}\text { High } \\
\text { Expression }\end{array}$ & \multirow[t]{2}{*}{$P$ Value $^{\mathrm{s}}$} \\
\hline & & No. $(\%)$ & No. $(\%)$ & \\
\hline \multirow{2}{*}{ Histologically benign versus tumour (G3, G4 or G5) } & Benign/BPH $\left(n^{\#}=364\right)$ & $184(51)$ & $180(49)$ & \multirow{2}{*}{$* * * P<0.0001$} \\
\hline & Gleason $3+4+5(n=602)$ & $193(32)$ & $409(68)$ & \\
\hline \multirow{2}{*}{ Histologically benign versus Gleason grade 3} & Benign/BPH $(n=364)$ & $184(51)$ & $180(49)$ & \multirow{2}{*}{$* * * P<0.0001$} \\
\hline & Gleason $3(n=301)$ & $104(35)$ & $197(65)$ & \\
\hline \multirow{2}{*}{$\begin{array}{l}\text { Histologically benign versus high grade tumour (G4 or } \\
\text { G5) }\end{array}$} & Benign/BPH $(n=364)$ & $184(51)$ & $180(49)$ & \multirow{2}{*}{$* * * P<0.0001$} \\
\hline & Gleason $4+5(n=301)$ & $89(30)$ & $212(70)$ & \\
\hline \multirow{2}{*}{ Benign \& Gleason 3 versus high grade tumour (G4 or G5) } & Benign/BPH+Gleason $3(n=665)$ & $288(43)$ & $377(57)$ & \multirow{2}{*}{$* * * P<0.0001$} \\
\hline & Gleason $4+5(n=301)$ & $89(30)$ & $212(70)$ & \\
\hline
\end{tabular}

Footnotes:

${ }^{*} n$ refers to the number of cores in each grouping.

${ }^{\$}$ Fisher's Exact Test where * and *** refer to $P<0.05$ and 0.0001 , respectively.

both PCa staging and progression (time to disease-free/ BCR-free survival), we sought to investigate whether altered $\mathrm{CpG}$ methylation of the $T B X A 2 R$ gene might play a role in the transcriptional regulation of TP $\alpha$ and TP $\beta$, potentially accounting for the observed differences in TP $\alpha$ and TP $\beta$ expression in PCa. Hence, a RT-PCR based approach was initially used to quantify relative TP $\alpha$ and TP $\beta$ mRNA expression in human prostate tissue or in the prostate adenocarcinoma $\mathrm{LNCaP}$ and $\mathrm{PC}-3$ cell lines and to determine whether their expression can be regulated in response to genomic demethylation. Quantitative RTPCR confirmed expression of both TP $\alpha$ and TP $\beta$ mRNA within the prostate-derived RNA and that there was, onaverage, a 10-fold higher level of TP $\alpha$ than TP $\beta$ mRNA expressed (Figure 4A). Furthermore, global genomic DNA demethylation with 5-Aza-2'-deoxycytidine (5-Aza-dC) led to significant increases in both TP $\alpha$ (2.8 -fold) and TP $\beta$ (4.5-fold) mRNA expression, and of the control GST- $\pi$ mRNA-amplicon, in the adenocarcinoma LNCaP and PC-3 cell lines (Figure 4B), confirming that the TBXA2R gene may be regulated by $\mathrm{CpG}$ methylation.

As stated while TP $\alpha$ and TP $\beta$ are encoded by the same $T B X A 2 R$ gene, they are transcriptionally regulated by two distinct promoters $[26,27]$ whereby Prm1, located $5^{\prime}$ of the transcription initiation (TI; nucleotide -289) site in exon/E1, exclusively regulates TP $\alpha$ while Prm3, located $5^{\prime}$ of the TI (nucleotide -12) within exon/E2, exclusively regulates TP $\beta$ expression (Figure 4C). Hence, a RT-PCR based approach was also used to clarify which promoters within the $T B X A 2 R$, namely Prm1 or Prm3, are regulating $\mathrm{TP} \alpha$ and TP $\beta$ expression in human prostate tissue or in the prostate adenocarcinoma $\mathrm{LNCaP}$ and $\mathrm{PC}-3$ cell lines. Consistent with previous findings in megakaryocytes $[26,27]$, Prm 1 and Prm 3 were confirmed to exclusively regulate TP $\alpha$ and TP $\beta$ expression, respectively, in the human prostate tissue and adenocarcinoma cell lines as evidenced by the finding that the $5^{\prime}$-most nucleotide (TI site) of TP $\alpha$ mRNA mapped to exon/E1 while the 5'most nucleotide of TP $\beta$ mRNA mapped to its TI site at nucleotide -12 located within exon/E2 (Figure 4C and 4D).

Thereafter, the $\mathrm{CpG}$ methylation profile of the Prm1 and Prm3 regions of the TBXA2R was assessed by interrogating the Infinium HumanMethylation450 BeadChip for changes in DNA methylation as a function of PCa progression (Figure 4E). Specifically, methylation levels of genomic DNA extracted from prostate tissue, dissected by laser-capture microscopy (LCM), from a subset of $45 \mathrm{PCa}$ patients mainly selected from the 
Table 2A: "Malmö TMA" - TP staining intensity/histology correlation

\begin{tabular}{|c|c|c|c|c|}
\hline \multirow{2}{*}{ Contingency Test } & \multirow{2}{*}{ Histology } & Low Expression & High Expression & \multirow{2}{*}{$P$ Value $^{\$}$} \\
\hline & & No. $(\%)$ & No. $(\%)$ & \\
\hline \multirow{2}{*}{ TP $\alpha$ : Benign versus Tumour } & Benign/BPH $\left(n^{\#}=325\right)$ & $88(27)$ & $237(73)$ & \multirow{2}{*}{$* * * P<0.0001$} \\
\hline & Tumour $(n=252)$ & $123(49)$ & $129(51)$ & \\
\hline \multirow{2}{*}{ TP $\beta$ : Benign versus Tumour } & Benign/BPH $(n=323)$ & $182(56)$ & $141(44)$ & \multirow{2}{*}{$* * * P<0.0001$} \\
\hline & Tumour $(n=263)$ & $99(38)$ & $164(62)$ & \\
\hline
\end{tabular}

Table 2B: "Malmö TMA" - TP staining intensity/biochemical recurrence correlation

\begin{tabular}{|c|c|c|c|c|}
\hline \multirow{2}{*}{ Contingency Test } & \multirow{2}{*}{ Histology } & Low Expression & High Expression & \multirow{2}{*}{$P$ Value $^{\$}$} \\
\hline & & No. $(\%)$ & No. $(\%)$ & \\
\hline TP $\alpha$ : Tumour Tissue & BCR Negative $\left(n^{\&}=148\right)$ & $78(53)$ & $70(47)$ & \multirow{2}{*}{$P=0.0570$} \\
\hline BCR Negative vs BCR Positive & BCR Positive $(n=68)$ & $26(38)$ & $42(62)$ & \\
\hline TP $\beta$ : Tumour Tissue & BCR Negative $(n=150)$ & $62(41)$ & $88(59)$ & \multirow{2}{*}{$* * P=0.0045$} \\
\hline BCR Negative vs BCR Positive & BCR Positive $(n=73)$ & $16(22)$ & $57(78)$ & \\
\hline
\end{tabular}

Table 2C: "Malmö TMA" - TP $\alpha / T P \beta$ staining intensity correlation in the tumour

\begin{tabular}{|c|c|c|c|c|}
\hline \multirow{3}{*}{ Contingency Test } & \multirow{3}{*}{ Histology } & $\mathbf{T P} \boldsymbol{\beta}$ & TP $\beta$ & \multirow{3}{*}{$P$ Value $^{\S}$} \\
\hline & & Low Expression & High Expression & \\
\hline & & No. $(\%)$ & No. $(\%)$ & \\
\hline \multirow{2}{*}{ TP $\alpha$ vs TP $\beta$ Staining Intensity } & TP $\alpha$ Low Expression $\left(n^{\dagger}=122\right)$ & $61(50)$ & $61(50)$ & \multirow{2}{*}{$* * * P<0.0001$} \\
\hline & TP $\alpha$ High Expression $(n=129)$ & $32(25)$ & $97(75)$ & \\
\hline
\end{tabular}

Footnotes:

${ }^{\#} n$ refers to the number of valid graded scores in the benign and tumour regions for patient cases.

${ }^{\&} n$ refers to the number of patient cases in each grouping where biochemical recurrence (BCR) status is known.

${ }^{\dagger} n$ refers to the number of patient cases in each grouping where valid $\mathrm{TP} \alpha$ and TP $\beta$ scoring are both available.

${ }^{\$}$ Fisher's Exact Test where ** and *** refer to $P<0.01$ and 0.0001 .

PCRC (Dublin-based) TMA ranging from benign/ $\mathrm{BPH}(N=10)$ through to the progressive stages of PCa including proliferative inflammatory atrophy (PIA; $N=7$ ), high-grade prostatic intraepithelial neoplasia (HGPIN; $N=6$ ), indolent (PCI; $N=7$ ), aggressive (PCA; $N=8)$ and metastatic (PCM; $N=7)$ PCa samples was evaluated by hybridization (Prm1, with 10 specific CpG probes; Prm3, with 3 specific $\mathrm{CpG}$ probes). While Prm1 (regulates $\mathrm{TP} \alpha$ mRNA expression) was found to lie within a hypomethylated region in the benign/BPH and PIA lesions ( $\beta$ value $\approx 0.2$ ), with little variation between individuals, methylation of Prm1 increased significantly in pre-invasive HGPIN tissues and primary and metastatic lesions ( $P=0.0002$, ANOVA). Whilst the increased Prm1 methylation is highly significant in the aggressive cohort $(P<0.01$; Figure 4E(i)), overall methylation intensities remain low $(\beta<0.5)$ within this Prm1 region of the $T B X A 2 R$ (Figure 4E(i)). In dramatic contrast to Prm1, the Prm3 region which regulates TP $\beta$ expression is highly hypermethylated in benign and precursor PIA lesions $(\beta$ value $\approx 0.8$ ), and there were significant decreases in Prm3 methylation observed within the metastatic cohort relative to the benign and precursor (PIA) lesions $(P=0.0022$, ANOVA; Figure 4E(ii)). Collectively, these data show highly significant differences in the $\mathrm{CpG}$ methylation status of Prm1 and Prm3 of the TBXA2R in both the benign/BPH tissue and also during the transition and progression of $\mathrm{PCa}$, whereby the changes that occur in $\mathrm{PCa}$ begin at the HGPIN stage and result in a nett increased methylation of Prm1 and a nett decreased methylation of Prm3, potentially accounting for the variable expression of $\mathrm{TP} \alpha$ in PCa and the more global increase in TP $\beta$ expression as a function of Gleason grade.

\section{DISCUSSION}

Prostate carcinogenesis and tumour development involves several critical steps including cell proliferation, survival, migration, invasion, and ultimately metastasis. Recently, several lines of evidence point to the role of the TXA $\mathrm{TP}_{2}$-TP signalling axis in cancer progression, not least from longitudinal studies showing that long-term daily use of aspirin reduces the risk of many common cancers (predominantly gastrointestinal, but also breast, 
lung, and prostate cancers), with numerous clinical trials completed/underway testing its benefits and of other NSAIDs/COXIBs in chemoprevention [6, 39, 40].

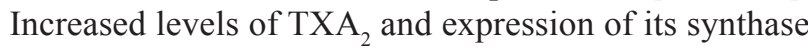
( $\mathrm{TXA}_{2}$ synthase) and its receptor, the TP, have been implicated in a number of prevalent cancers [8], including in bladder [41], prostate [12, 13], colorectal [14, 15] and non-small cell lung cancer [16]. However, while clinical evidence for the role of the $\mathrm{TXA}_{2}-\mathrm{TP}$ axis in cancer progression is increasing, with the exception of bladder cancer [11] previous studies have not investigated the role of the individual TP $\alpha$ or TP $\beta$ isoforms in cancer or indeed in other diseases in which $\mathrm{TXA}_{2}$ has been implicated. While TP $\alpha$ and TP $\beta$ are encoded by the same gene, they are differentially expressed being under the control of different promoters [24-27] within the
$T B X A 2 R$, and appear to be functionally distinct displaying both common/over-lapping but also isoform-specific physiologic roles. Although showing similar coupling to Gq/phospholipase C $\beta$ and to Gq/G12-RhoA [10, 18], TP $\alpha$ and TP $\beta$ differentially regulate other effectors including the PRKs $[18,19]$ and are themselves differentially regulated [22, 42-44]. Critically and in this regard, signalling by $\mathrm{TP} \alpha$, but not TP $\beta$, is completely inhibited by the counter-regulatory anti-platelet and vasodilatory agents prostacyclin and nitric oxide mediated by direct protein kinase (PK)A and PKG phosphorylation of TP $\alpha$ at $\operatorname{Ser}^{329}$ and $\mathrm{Ser}^{331}$, respectively, the very first divergent residues between TP $\alpha$ and TP $\beta[43,44]$. The conclusion from those studies is that TP $\alpha$ is essential for haemostasis/ thrombosis, while the role of TP $\beta$ in this pathophysiologic process remains less clear $[43,44]$.

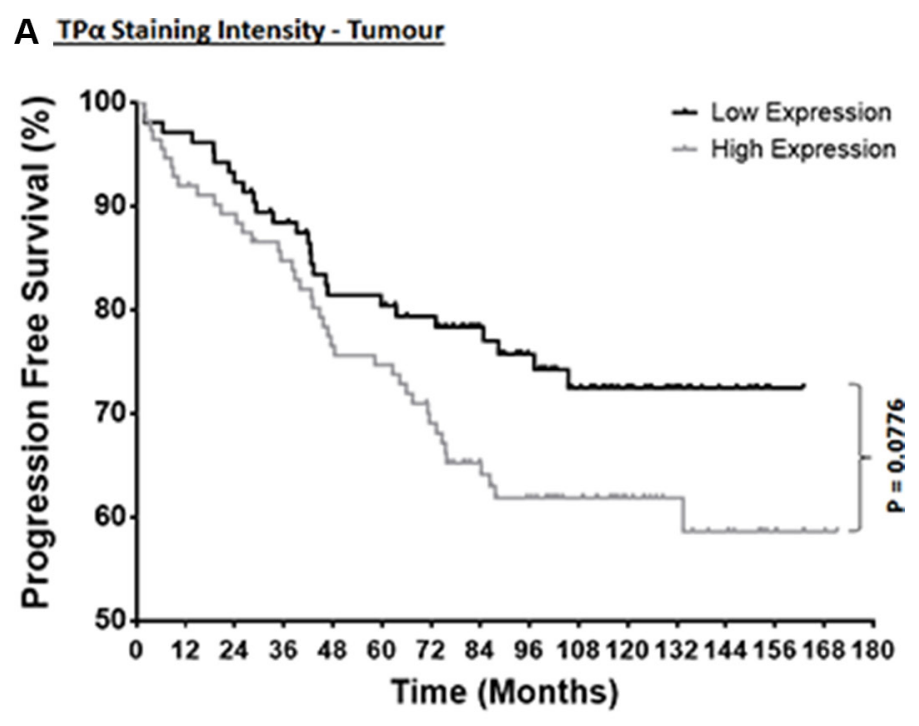

B $\underline{\text { TPB Staining Intensity - Tumour }}$

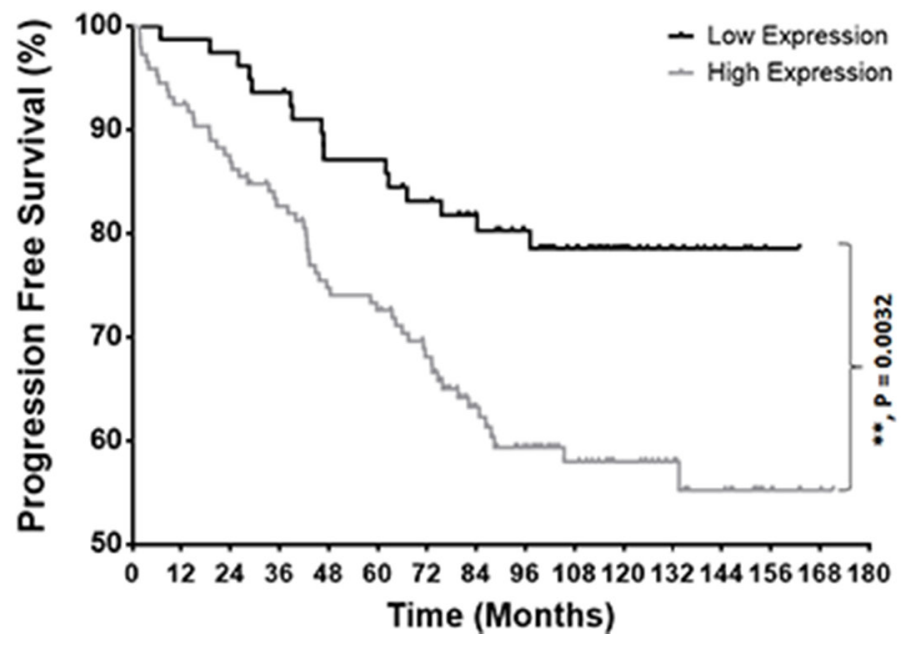

Figure 3: Correlation of TP $\alpha$ and TP $\beta$ expression with the progression to BCR. Kaplan-Meier survival analysis of the correlation between low or high levels of TP $\alpha$ (Panel A) and TP $\beta$ (Panel B) expression with time to onset of BCR using the "Malmö TMA" dataset. BCR-free survival was compared between the expression groups by Kaplan-Mantel-Cox log rank comparison with GehanBreslow-Wilcoxon correction test, where ** indicates $P<0.01$. 
A

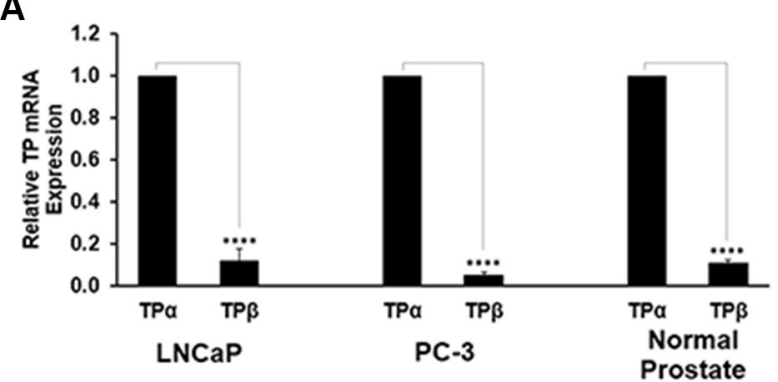

B

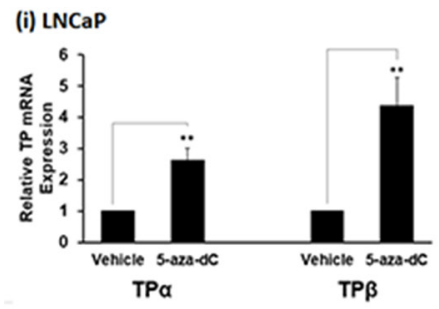

(ii) PC-3

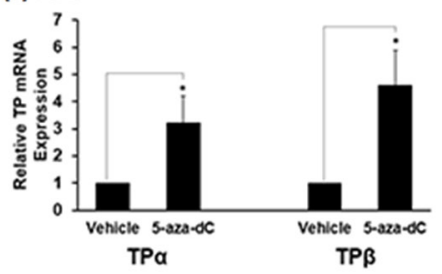

(iii) GST- $\pi$ Control (LNCaP)

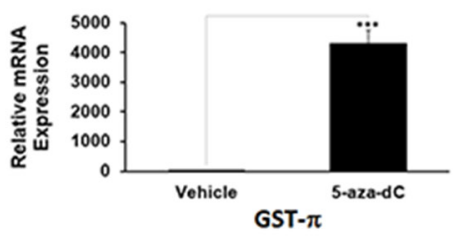

C

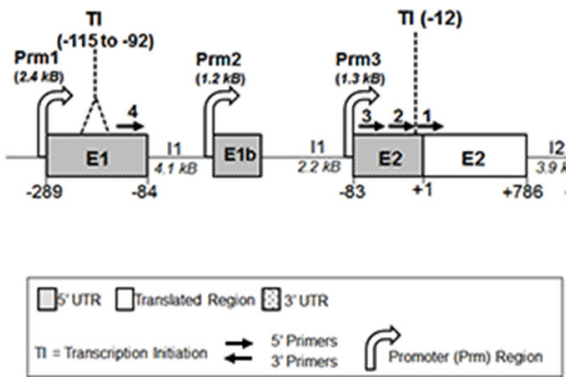

D

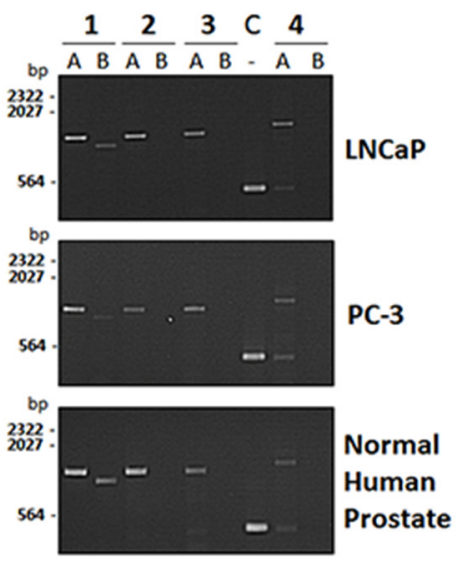

E

(i) Prm1

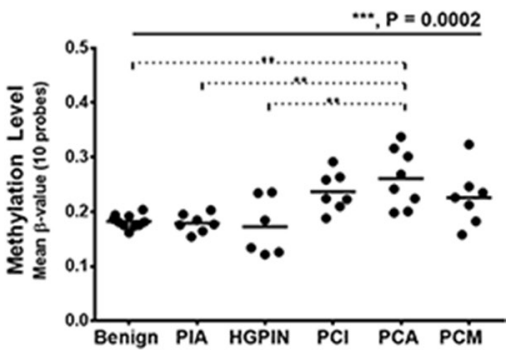

(ii) Prm3

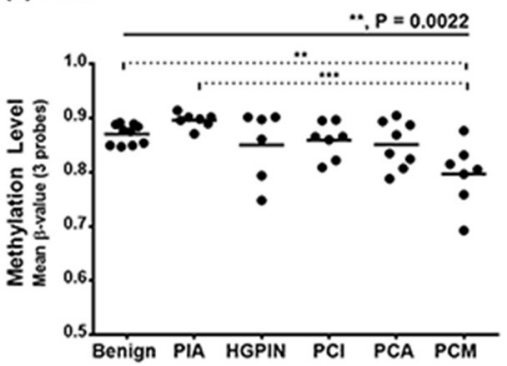

Figure 4: Transcriptional regulation \& methylation of the TBXA2R in PCa. Panel (A) qRT-PCR analysis of TP $\alpha$ and TP $\beta$ mRNA expression levels in LNCaP, PC-3 cells and normal human prostate. All data was normalized relative to 18S rRNA levels. Data are presented as mean relative TP $\alpha$ or TP $\beta$ mRNA expression ( \pm SEM, $n \geq 3$ ). Panel (B) qRT-PCR analysis of TP $\alpha$ and TP $\beta$ mRNA expression levels in LNCaP (i) and PC-3 (ii) cells, along with GST- $\pi$ mRNA expression levels in LNCaP (iii) cells, treated with $5 \mu \mathrm{M} 5$-Aza-dC at 24-hr intervals for 5 days or, as control, with vehicle $(0.005 \%$ DMSO). Data were normalized relative to $18 \mathrm{~S}$ rRNA levels in each case, and are presented as mean expression ( \pm SEM, $n \geq 3$ ) relative to those levels found in the vehicle-treated cells. Panel (C) A schematic of the human TBXA2R gene showing the relative positions of exon (E)1, E1b, E2, E3, E3b, intron (I) 1, I2, I3b and the 3 promoters (Prm)1, Prm2 and Prm3, located 5' of E1, E1b and E2, respectively. The position of the major transcription initiation (TI) sites on the TP $\alpha(-115$ to -92 , within EI) and TP $\beta\left(-12\right.$, within E2) mRNAs, and of the $5^{\prime}$ and $3^{\prime}$ untranslated regions (UTR) in addition to the translated regions within the TP $\alpha$ and TP $\beta$ mRNAs are also shown. All nucleotide numbering is assigned relative to the translation start site ATG at nucleotide +1. Panel (D): Agarose gel electrophoresis of RT-PCR products derived from total RNA extracted from PC-3 and LNCaP cells or normal human prostate tissue. To determine which promoter (Prm1 or Prm3) is driving TP $\alpha$ and/or TP $\beta$ mRNA expression, a series of 5' primers located within E1 (Primer 4) or E2 (Primers 1, 2 or 3) were used in PCR experiments in combination with the TP $\alpha$ (Primer A) or TP $\beta$ (Primer B) specific 3' primers. For TP $\alpha$, amplicons were generated for all 5' primers (Primers 1-4) used in combination with Primer A (TP $\alpha$ specific), but in the case of TP $\beta$, amplicons were generated with the $5^{\prime}$ primer Primer 1, but not Primers 2-4, in combination with Primer B (TP $\beta$ specific) showing that the major transcription initiation (TI) sites of TP $\alpha$ mRNA mapped to the TI within EI ( -115 to - 92) but for the TP $\beta$ mRNA mapped to the TI (at -12) within E2. The control (C) lane shows amplicons for GAPDH. Panel (E): Data from hybridization analysis of the Infinium Human Methylation 450K Beadchip with CpG probe sets for the (i) Prm1 or (ii) Prm3 regions of the TXBA2R gene. Scatter plots show the distribution of methylation levels ( $\beta$ values) in LCM-dissected specimens from benign tissues $(N=10)$, proliferative inflammatory atrophy (PIA; $N=7)$ and high-grade prostatic intraepithelial neoplasia (HGPIN; $N=6)$ specimens, and from indolent (PCI; $N=7$ ), aggressive (PCA; $N=8$ ) and metastatic (PCM; $N=7$ ) PCa samples. Differences were analysed by one-way ANOVA group comparisons (solid black line) and Tukey's multiple comparisons (dotted lines). In all panels, ${ }^{*},{ }^{* *},{ }^{* * *}$ and ${ }^{* * * *}$ indicate $P<0.05,0.01,0.001$ and 0.0001 , respectively. 
Mechanistically, the ability of the $\mathrm{TXA}_{2}-\mathrm{TP}$ axis to regulate tumour development and metastasis can be explained by the ability of $\mathrm{TP} \alpha / \mathrm{TP} \beta$ to regulate key mitogenic/ERK- and RhoA-mediated signalling cascades $[9,10]$ and, potentially, by its ability to regulate local inflammation and immunity [45-50]. Furthermore, and in the context of $\mathrm{PCa}, \mathrm{TP} \alpha$ and TP $\beta$ differentially regulate signalling by the PRKs, a RhoA effector known to act as a specific gate-keeper of androgen receptor (AR) -mediated chromatin remodelling (H3pThr11) and hence, androgendependent gene expression within the prostate [19, 32-34]. In fact, due to the ability of the PRKs to regulate androgeninduced gene expression even in the absence of androgens, such as in situations that may mimic androgen deprivation therapy (ADT) in the clinical setting, aberrant activation of the PRKs has been proposed as one possible cellular mechanism that leads to CRPC, the metastatic lethal form of PCa that occurs on failure of anti-androgen therapies [4]. Hence, the discovery that the $\mathrm{TXA}_{2}-\mathrm{TP}$ signalling axis can directly activate the PRKs to induce the essential chromatin modifications (H3pThr11) necessary to support AR-mediated gene expression within the prostate even in the absence of androgens per se led us to interrogate the role of TXA $\mathrm{TH}_{2}$ in $\mathrm{Pa}$, including in CRPC $[19,35]$.

In the current study, we evaluated the expression profiles of both TP $\alpha$ and TP $\beta$ in TMAs representative of benign prostate tissue and of the different Gleason grades (3, 4, and 5) of PCa obtained following prostatectomy through IHC staining using isoform-specific antibodies. The majority of anti-TP $\alpha$ immunoreactivity within the prostate epithelium was cytoplasmic. In addition, abundant TP $\alpha$ expression was also evident within the smooth muscle cells of the fibromuscular stromal regions, consistent with the recognised contractile role of $\mathrm{TXA}_{2}$ in the prostate [51]. While less abundant than $\mathrm{TP} \alpha$ within the prostate stroma, the majority of antiTP $\beta$ immunoreactivity within the luminal epithelium was cytoplasmic, but substantial nuclear staining of TP $\beta$ was also evident in several specimens. Predominant cytoplasmic expression/IHC staining for TP $\alpha$ and TP $\beta$ is not unexpected bearing in mind that both TPs undergo agonist-induced internalization [44, 52] while under tonic/resting conditions, a substantial component of both TP $\alpha$ and TP $\beta$ localise to the endoplasmic reticulum and Golgi complex [53]. Furthermore, at any given time, a proportion of TP $\beta$ is stored in intracellular pools of perinuclear recycling endosomes, from which they may be subsequently trafficked to the cell surface as required [54]. Noteworthy, whilst nuclear expression of TP $\beta>\operatorname{TP} \alpha$ was also evident in certain cores of the TMAs used in the current study, there was no correlation between nuclear expression of either TP with any of the pathological parameters (Gleason grade or BCR) examined.

Initially, through the use of the "PCRC TMA" and borne out by findings from the "Malmö TMA" and from a third independent Dublin-based TMA of 61
PCa patients across 450 tissue-cores (data not shown), cytoplasmic expression of the TP $\beta$ isoform was found to be significantly increased in prostate tumours relative to benign tissue, with increasing expression of TP $\beta$ significantly correlating with an increase in Gleason grade and pathological stage. Furthermore, while expression of TP $\alpha$ was found to be variably increased or decreased across all 3 TMAs screened within this study, there was no overall direct correlation between $\mathrm{TP} \alpha$ expression with Gleason grade or pathological stage observed. These findings involving 3 independent TMAs, totalling 529 PCa cases and 2841 benign/malignant cores, are entirely in keeping with the independent expression/transcriptional regulation of TP $\alpha$ and TP $\beta$ [24-27]. Notably, a previous study conducted on full-face PCa tissue samples from a small patient cohort $(N=46)$ using an antibody which does not discriminate between the individual TP $\alpha / \mathrm{TP} \beta$ isoforms found that expression of the TP was increased in the malignant relative to benign tissue, with advanced pathological stages and poorly-differentiated tumours having the highest expression levels [12].

While the vast majority of prostate tumours remain asymptomatic [1, 55], following surgery or radiation therapy approximately one third of patients with localised PCa experience disease relapse, in what is diagnostically termed "biochemical recurrence (BCR)" or PSA failure [3]. Hence, using the "Malmö TMA" for which 10-yr follow-up clinical records are available, the association between TP $\alpha$ and TP $\beta$ expression with patient-progression to BCR was investigated. Strikingly, high levels of TP $\beta$ expression were associated with significantly increased risk of BCR and shorter BCR-free survival time following surgery. For $\mathrm{TP} \alpha$, while not quite achieving statistical significance using the binary low/high scoring approach, there was a considerable trend with 'high TP $\alpha$ expression' levels being associated with $\operatorname{BCR}(P=0.057)$ and shorter BCR-free survival time $(P=0.0776)$. However, the alternative ordinal scoring approach showed that expression of TP $\alpha$ does in fact correlate with time-toprogression to $\mathrm{BCR}(P=0.0291)$. The fact that the correlation between high $\mathrm{TP} \alpha$ expression and BCR or BCR-free survival time did not reach significance using all approaches is not surprising given that the relative ratio of low/decreased versus high/increased expression of $\mathrm{TP} \alpha$ in the tumour regions was evenly distributed (50:50). However, it was notable that those patient cases with high TP $\alpha$ expression also showed a strong correlation with high TP $\beta$ expression $(P=0.0001$; Table $2 \mathrm{C})$ showing that increased expression of either TP $\alpha, \mathrm{TP} \beta$ or both TP isoforms trends toward the poorer outcome. In line with that suggestion, while $34 \%(P=0.0396)$ of patients in the Malmö TMA displaying high levels of TP $\beta$ in the tumour progressed to BCR, that figure increased to $41 \%$ $(P=0.0017)$ in patients showing both high TP $\alpha$ and TP $\beta$ expression in the tumour region, where in both instances the mean time to progression to BCR was 42-43 months 
post-surgery. Taken together, these findings suggest that increased expression of TP $\beta$, or of TP $\alpha$ or a combination of TP $\alpha / \mathrm{TP} \beta$ expression levels, may serve as diagnostic biomarkers and clinical predictors of $\mathrm{PCa}$ disease recurrence. Noteworthy, additional multivariate analyses herein suggested that expression of TP $\alpha$ and of TP $\beta$ may indeed provide independent prognostic value over and above that provided solely through histological Gleason scoring or pathological tumour staging. Confirming the predictive power of these findings is indeed advisable through investigation in other independent patient cohorts, including with additional or longer term followup clinical histories or in TMAs that might enable combined correlation of TP expression with Gleason grade, tumour staging and BCR. However, based on the findings from this study, it is indeed possible to suggest that employing a similar approach (i.e. using TP $\alpha$ and/or TP $\beta$ isoform specific antibodies), expression of TP $\alpha$ and/ or TP $\beta$ could be histologically assessed at an early stage post-diagnosis or post-radical prostatectomy to improve the diagnostic and prognostic evaluation of patients with $\mathrm{PCa}$ and can help stratify patients with a higher likelihood of progressing to disease relapse/BCR, who would require additional therapies. At the same time, in conjunction with the use of other histological biomarkers, the application of this strategy may help to avoid unnecessary therapies, and the associated complications thereof, in patients deemed to be at a lower risk of PCa recurrence. While our histologic evaluations were based on TMAs derived from radical prostatectomies, additional evaluations of biopsy samples from PCa patients may enable clarification on whether assessment of TP $\alpha$ and/or TP $\beta$ expression might also be used to as a useful biomarker for determining whether a patient may require radical prostatectomy or not.

In normal mammalian development, $\mathrm{CpG}$ DNA methylation/demethylation serves to modulate gene expression [56], and plays a major role in cancer through the transcriptional silencing or activation of critical growth regulators such as tumour suppressor genes or oncogenes, respectively [38]. As stated, expression of TP $\alpha$ is under the control of Prm1 within the TBXA2R gene, while TP $\beta$ is under the control of Prm3 [26, 27]. While a recent study revealed that the tumour suppressors Wilms' tumour (WT) 1 and hypermethylated in cancer (HIC)1 transcriptionally regulate $\mathrm{TP} \alpha$ expression through binding to $c i s$-elements within Prm1 in both prostate and breast cancer cell lines [57], to the best of our knowledge no study has yet investigated the mechanisms governing the transcriptional regulation of TP $\beta$ through Prm3 in similar settings. Herein, it was confirmed that Prm1 and Prm3 exclusively regulate TP $\alpha$ and TP $\beta$ mRNA expression, respectively, both in normal human prostate and in the $\mathrm{PCa}$ adenocarcinoma LNCaP and PC-3 cell lines and that expression of both mRNAs' can be increased in response to global genomic demethylation with 5-Aza-dC. Bearing in mind our findings that the histological expression of
$\mathrm{TP} \alpha$ and TP $\beta$ are significantly but differentially altered as a function of $\mathrm{PCa}$ staging and progression, but that increased expression of either isoform is specifically associated with disease relapse (BCR) and shorter BCRfree survival time, it was of interest to investigate the patterns of DNA methylation within similar PCa cohorts. Significant changes in the methylation landscape within the Prm 1 and Prm 3 regions of the $T B X A 2 R$ were observed across a range of benign, precursor prostate neoplasms and increasing PCa staging. Specifically, and consistent with the higher level of TP $\alpha$ mRNA expression in the prostate and clonal cell lines, it was found that Prm1 is hypomethylated in benign tissues and precursor lesions but that it undergoes increased methylation across primary and metastatic PCa stages potentially accounting for the overall reduced level of TP $\alpha$ such as generally observed across the "Malmö TMA". Conversely, the Prm3 region is highly hypermethylated in benign and precursor lesions, with significant losses of methylation observed within certain aggressive and metastatic PCa samples, potentially accounting for the overall increased expression of TP $\beta$ as a function of Gleason grade and associated with both TMAs. These investigations clearly show that the $T B X A 2 R$ gene is subject to altered $\mathrm{CpG}$ methylation as a function of $\mathrm{PCa}$ staging. Moreover, they prompt detailed methylation sequencing analysis of the TBXA2R to determine whether the alterations in TP $\alpha$ and/or TP $\beta$ expression observed in $\mathrm{PCa}$ tissue is due to altered methylation of specific cisacting elements within Prm1 or Prm3 controlling TP $\alpha$ and TP $\beta$ transcriptional expression. It is indeed notable that increased expression of TP $\beta$, without concomitant changes in TP $\alpha$ expression have been found in clinically derived tissue from patients with high-grade bladder cancer $(N=43)$ and high levels of TP $\beta$ in those patients correlated with reduced overall survival [11].

In conclusion, data presented herein propose a novel diagnostic and prognostic potential for TP $\alpha$ and TP $\beta$ in the histopathological assessment of PCa. While TP $\alpha$ and TP $\beta$ are differentially expressed and independently regulated, increased levels of TP $\beta$, TP $\alpha$ or both correlated with increased risk of recurrence and reduced diseasefree survival time. Moreover, correlation of TP $\alpha$ and TP $\beta$ expression with pathological staging showed what high TP $\alpha$ expression was significantly associated with the organ-confined pT2 cases while, in stark contrast, high TP $\beta$ expression was significantly associated with the invasive pT3 cases. We also show that altered $\mathrm{CpG}$ methylation of the Prm1 and Prm3 regions of TBXA2R gene can specifically modulate TP $\alpha$ and TP $\beta$ expression, respectively, during the progression of PCa. Following detailed investigation of the trans-acting transcription factors regulating Prm1/TP $\alpha$ and Prm3/TP $\beta$ in PCa settings, interrogation of the $\mathrm{CpG}$ methylation status of the $T B X A 2 R$ might also serve as a key clinical marker with which to stratify higher risk patients and to tailor treatment options. Taken together, these studies provide 
significant credence to the functional role of the TXA - -TP signalling axis in cancer progression and to the growing body of evidence for the prophylactic benefits of aspirin in reducing cancer risk by lowering $\mathrm{TXA}_{2}$ levels. Whether there is a particular added clinical benefit of aspirin therapy in those patients showing elevated TP $\beta$ or TP $\alpha$ needs to be considered. Furthermore, investigation of the therapeutic potential of targeting TP $\beta$ and/or TP $\alpha$ through the use of receptor antagonists, such as in adjuvant therapy, for PCa treatment may also be warranted.

\section{MATERIALS AND METHODS}

\section{Tissue specimens and tissue microarrays}

Full-face formalin-fixed and paraffin-embedded radical prostatectomy samples $(N=17)$ were obtained through ethical consent from St. Vincent's University Hospital (Dublin, Ireland). Tissue microarrays (TMAs) from two distinct patient cohorts were used. The first TMA ("PCRC TMA", Table 3A), used to investigate TP $\alpha$ and TP $\beta$ immunohistochemical (IHC) staining/expression with Gleason grading, was constructed from a populationbased cohort of $130 \mathrm{PCa}$ patients who underwent radical prostatectomy at one of three Dublin (Ireland) hospitals and collected as part of the Prostate Cancer Research Consortium (PCRC) bioresource. At the point of diagnosis, these specimens were reviewed and graded according to the Gleason scoring system. Cores from these cases included a variety of histological Gleason scores, ranging from 6 to 10, where three cores of each histological stage (Benign/BPH and Gleason grade 3, 4 and 5 carcinomas) were taken from each case, where available. The second TMA ("Malmö TMA", Table 3B), used to investigate correlation of TP $\alpha$ and TP $\beta$ expression with disease recurrence, was constructed from radical prostatectomy samples from 338 PCa patients who underwent surgery at Skåne University Hospital (Malmö, Sweden), and for which clinical follow-up data (minimum 10 year followup) and pathological staging is also available. Cores taken from this patient cohort included a variety of histological Gleason scores, ranging from 5 to 10, where two tissue cores were taken from each of the benign, primary (predominant) and secondary Gleason grade patterns, where available. The use of tissue samples was approved by the respective Ethics Committee of the participating institutions.

\section{Immunohistochemistry}

Serial sections of formalin fixed, paraffin embedded full-face prostate tissue or TMA blocks were sectioned at 4 $\mu \mathrm{m}$ thickness and baked onto slides at $50-56^{\circ} \mathrm{C}$ for at least $60 \mathrm{~min}$. Sections were dewaxed in two changes of xylene $(2 \times 10 \mathrm{~min})$ and rehydrated through a series of decreasing alcohol solutions $(100 \%, 3 \mathrm{~min} \times 2 ; 95 \%, 1 \mathrm{~min} ; 80 \%$,
$1 \mathrm{~min}$ ) before being washed in distilled water. Endogenous peroxidase activity was blocked by incubation in 3\% hydrogen peroxide, prepared in methanol, for $10 \mathrm{~min}$ at R.T., followed by washing of tissue sections in PBS. Non-specific binding was blocked by incubating the tissue sections for $30 \mathrm{~min}$ at R.T. with $5 \%$ goat serum in PBS (Blocking Buffer) to which Avidin D (4 drops $/ \mathrm{ml}$ of Blocking Buffer; Vector Labs Avidin/Biotin Blocking kit) was added to block endogenous biotin. Thereafter, sections were incubated overnight at $4^{\circ} \mathrm{C}$ in a humidified chamber with primary $\left(1^{\circ}\right)$ antibody, prepared in Blocking Buffer and containing Biotin (4 drops $/ \mathrm{ml}$ of Blocking Buffer; Vector Labs Avidin/Biotin Blocking kit), where affinitypurified rabbit anti-TP $\alpha(12 \mu \mathrm{g} / \mathrm{ml})$ or anti-TP $\beta(1.3 \mu \mathrm{g} / \mathrm{ml})$ antibodies $[10,36]$ were used to detect TP $\alpha$ or TP $\beta$. As controls, either the $1^{\circ}$ antibody was omitted, or the $1^{\circ}$ anti-TP $\alpha$ or anti-TP $\beta$ antibodies were pre-incubated at R.T. for $1 \mathrm{~h}$ with a 5 -fold $(\mathrm{w} / \mathrm{w})$ excess of either the immunogenic ТP $\alpha$ (aa 329-343) or ТP $\beta$ (aa 391-407) peptides or a randomised non-competitor peptide. Sections were washed in PBS, prior to incubation for 30 min with biotinylated goat anti-rabbit secondary antibody (1:500 dilution), prepared in Blocking Buffer. After washing, tissue sections were incubated with streptavidin horseradish peroxidase (HRP; 1 in 1500, prepared in Blocking buffer) for $30 \mathrm{~min}$ at room temperature, followed by incubation with the chromogen 3,3'-diaminobenzidine (DAB) substrate $(0.05 \% \mathrm{DAB}, 0.015 \%$ hydrogen peroxide in PBS) for 1-5 min. Tissue sections were counterstained with haematoxylin, dehydrated through increasing alcohol series and xylene $(2 \times 10 \mathrm{~min})$ prior to mounting in DPX. Slides were imaged using a Zeiss microscope and AxioVision software or digitally scanned using the Aperio ImageScope system.

\section{TMA scoring \& statistical analysis}

Each TMA core was reviewed to verify the presence of benign tissue or adenocarcinoma and to annotate the Gleason grade of the tumour, where applicable (C.S./ E.W.K.). Cytoplasmic immunoreactivity/expression of TP $\alpha$ and TP $\beta$ in the benign and tumour prostate epithelium across both TMAs used in the study was independently assessed by two pathologists (C.S./E.W.K.). For the purpose of statistical analysis, expression in $10 \%$ or more cells was required for a positive score, and was graded according to the following scale: 0 , no staining; 1 , faint but clearly detectable staining in $>10 \%$ of epithelial cells; 2 , moderate staining in $>10 \%$ of epithelial cells; and 3 , strong staining in $>10 \%$ of epithelial cells. Occasionally, in cases where there was marked variability, an intermediate staining intensity score (i.e. $0.5,1.5,2.5)$ was assigned. Some unusable cores were found in the TMAs due to missing tissue, cancer necrosis, or insufficient cancer cells and, hence, these cores were excluded from the study. The staining intensities of TP $\alpha$ and TP $\beta$ in 
Table 3A: "PCRC TMA" - characteristics and composition

\begin{tabular}{|c|c|}
\hline Number of Patients & 130 \\
\hline Patient Age (Mean \pm SD) & $61.2 \pm 6.53 \mathrm{yrs}$ \\
\hline PSA At Surgery (Mean \pm SD) & $8.35 \pm 3.49 \mathrm{ng} / \mathrm{ml}$ \\
\hline Gleason Scoring & Number $^{\text {s }}$ \\
\hline 6 & 34 \\
\hline $7(3+4)$ & 39 \\
\hline $7(4+3)$ & 25 \\
\hline 8 & 21 \\
\hline 9 & 11 \\
\hline Clinical Staging & Number \\
\hline T2a/b & 11 \\
\hline T2c & 57 \\
\hline T3a & 47 \\
\hline T3b & 15 \\
\hline TMA Composition & Number \\
\hline Total Cores & 1038 \\
\hline Mean Cores/Patient & 7.9 \\
\hline Benign/BPH Cores & 389 \\
\hline Gleason 3 Cores & 320 \\
\hline Gleason 4 Cores & 272 \\
\hline Gleason 5 Cores & 45 \\
\hline Miscellaneous/Other & 12 \\
\hline
\end{tabular}

Footnotes:

${ }^{\$}$ refers to the number of patient cases.

"refers to the number of cores.

†refers to cores that could not be graded and thus eliminated from all statistical analyses.

the cytoplasm of the benign and tumour epithelium was then further divided into two groups: "low expression" (score $<2$ ) included those with negative or weak staining and "high expression" (score $\geq 2$ ) included those with moderate or strong reactivity. Statistical analyses of differences were carried out using one-way ANOVA followed by post hoc Dunnett's multiple comparison $t$ tests, as indicated. Fisher exact tests were performed on $2 \times 2$ contingency tables to test association of $\mathrm{TP} \alpha / \mathrm{TP} \beta$ IHC score (high expression $[\geq 2]$ and low expression $[<2]$ ) with Gleason grading. Kaplan-Meier analyses were used for survival comparisons to test association of $\mathrm{TP} \alpha /$ TP $\beta$ IHC score (high expression [ $\geq 2]$ and low expression $[<2]$ ) with progression to BCR. All values are expressed as mean \pm standard error of the mean (SEM). $P$-values $<0.05$ were considered to indicate statistically significant differences, where $* * *$ and $* * *$ indicate $P<0.05$, $P<0.01$ and $P<0.001$, respectively. Statistical analyses were performed using GraphPad Prism, version 5.00.

\section{Reverse transcriptase (RT)-PCR \& real-time quantitative RT-PCR (qRT-PCR) analysis}

The human PCa adenocarcinoma PC-3 and LNCaP cell lines, obtained from the American Type Culture Collection and confirmed mycoplasma-free, were routinely cultured at $37^{\circ} \mathrm{C}$ in a humid atmosphere with $5 \% \mathrm{CO}_{2}$ as described previously [19]. Human prostate total RNA (ThermoFisher Scientific) or total RNA, extracted from PCa cell lines using TRIzol reagent (Sigma), was DNase-treated and was converted to first-strand $\left(1^{\circ}\right)$ cDNA with SuperScript $^{\circledR}$ III Reverse Transcriptase (Invitrogen), as previously described $[26,27]$. For TP $\alpha / \mathrm{TP} \beta$-typing studies, conventional non-quantitative/end-point reverse transcriptase (RT)PCR analysis was performed essentially as previously described [26, 27], where the specific primers and respective target regions are detailed in Supplementary Table S1A. 
Table 3B: "Malmö TMA" - characteristics and composition

\begin{tabular}{|c|c|}
\hline Number of Patients & 338 \\
\hline Patient Age (Mean \pm SD) & $62.9 \pm 5.75 \mathrm{yrs}$ \\
\hline PSA At Surgery (Mean \pm SD) & $9.21 \pm 6.05 \mathrm{ng} / \mathrm{ml}$ \\
\hline \# Patients with Recurrence (\%) & $99(30 \%)$ \\
\hline Time to Recurrence (Mean \pm SD) & $44.61 \pm 30.86$ months \\
\hline Gleason Scoring & Number \\
\hline 5 & 34 \\
\hline 6 & 110 \\
\hline $7(3+4)$ & 107 \\
\hline $7(4+3)$ & 54 \\
\hline 8 & 4 \\
\hline 9 & 20 \\
\hline 10 & 1 \\
\hline Not Known & 8 \\
\hline Pathological Staging & Number \\
\hline pTX & 14 \\
\hline pT2 & 165 \\
\hline pT3 & 157 \\
\hline pT4 & 2 \\
\hline TMA Composition & Number $^{\text {\# }}$ \\
\hline Total Cores & 1355 \\
\hline Mean Cores/Patient & 4.1 \\
\hline
\end{tabular}

Footnotes:

${ }^{s}$ refers to the number of patient cases.

"refers to the number of cores.

†refers to patient cases that could not be graded and thus eliminated from all statistical analyses.

To quantify TP $\alpha$ or TP $\beta$ mRNA expression or investigate the effect of alterations in DNA $\mathrm{CpG}$ methylation on TP $\alpha$ or TP $\beta$ mRNA expression in response to global genomic DNA demethylation, $\mathrm{PC}-3$ or $\mathrm{LNCaP}$ cells were incubated for 5 days with either $5 \mu \mathrm{M}$ 5-Aza2'-deoxycytidine (5-Aza-dC; Sigma) or, as controls, with vehicle $(0.005 \%$ DMSO), where in all cases drug/vehicle was replaced every $24 \mathrm{hr}$. Cells were then harvested, total RNA extracted (TRIzol reagent) and converted to $1^{\circ} \mathrm{cDNA}$ as previous. Real-time quantitative RT-PCR (qRT-PCR) analysis was performed using the $\mathrm{SyBr}$ Green reaction kit, as previously described [57], where the primers and respective target regions are detailed in Supplementary Table S1B. As a positive control, changes in glutathione $S$-transferase (GST)- $\pi$ mRNA expression levels in LNCaP cells were quantified using TaqMan technology using a gene-specific expression assay (Hs00168310.m1; Applied Biosystems). To obtain $\Delta \mathrm{Ct}$ values, levels of TP $\alpha$, TP $\beta$ and GSTP1 mRNA expression were normalized relative to $18 \mathrm{~S}$ rRNA levels. $\Delta \Delta \mathrm{Ct}$ values were calculated using control/ vehicle $\Delta \mathrm{Ct}$ values. Relative TP $\alpha$, TP $\beta$ and GST $-\pi$ mRNA expression levels were calculated using the formula $2^{-\Delta \Delta \mathrm{Ct}}$ [58], and data is presented as mean changes in mRNA expression relative to control levels, assigned a value of 1 (Relative expression \pm SEM, $n \geq 3$ ). Results were obtained from RNA extracted from three independent
PC-3 or LNCaP cell treatments, with multiple independent cDNAs generated from each treatment, and where qRTPCR samples were run in duplicate in all cases.

\section{Genomic methylation analysis}

Tissues used to investigate the $\mathrm{CpG}$ methylation status of the TBXA2R gene as a function of $\mathrm{PCa}$ progression were ethically sourced via the Prostate Cancer Research Consortium (PCRC) from one of three Dublin (Ireland) hospitals or, for the metastatic patient cohort, from the University of Washington Medical Center via their Prostate Cancer Donor Program. Six pathological stages were chosen to reflect the progression of $\mathrm{PCa}$; benign prostate $(N=10)$, proliferative inflammatory atrophy (PIA; $N=7$ ), high-grade prostatic intraepithelial neoplasia (HGPIN; $N=6$ ), indolent (PCI; $N=7$ ), aggressive (PCA; $N=8)$ and metastatic $(\mathrm{PCM} ; N=7) \mathrm{PCa}$ stages. Benign tissues were obtained from FFPE radical cystoprostatectomy specimens with no evidence of $\mathrm{PCa}$, while PIA, HGPIN and PCa samples were obtained from FFPE radical prostatectomy specimens. Indolent tumours were defined as Gleason grade 3, pT2, pre-operative PSA $\leq 10 \mathrm{ng} / \mathrm{ml}$ with no evidence of biochemical or clinical recurrence. Aggressive tumours were defined as Gleason grades $4 / 5$, pT3, with seminal vesicle and/or lymph node 
involvement and biochemical recurrence. Metastatic tumours were sampled from multiple tissue sources (liver, lymph node and adrenal). Laser capture microdissection was performed using the Arcturus XT to enrich for prostatic epithelial cells in each sample. Genomic DNA was extracted using the QIAamp DNA micro kit and was quantified using Qubit fluorometric analysis. DNA isolated from the microdissected samples underwent FFPE damage restoration (Infinium) and bisulphite modification (Zymo Research) prior to processing on the Infinium HumanMethylation450 BeadChip Assay platform (Illumina, Inc., San Diego, CA) according to manufacturer's instructions. Methylation call data were subsequently analyzed using the RnBeads pipeline [59]. Differences were analysed by one-way ANOVA group comparisons and Tukey's multiple comparisons.

\section{Abbreviations}

5-Aza-dC, 5-Aza-2'-deoxycytidine; ADT, androgen deprivation therapy; $\mathrm{AR}$, androgen receptor; $\mathrm{BCR}$, biochemical recurrence; $\mathrm{BPH}$, benign prostatic hyperplasia; COX, cyclooxygenase/prostaglandin $\mathrm{G}_{2} /$ $\mathrm{H}_{2}$ synthase; CRPC, castrate resistant prostate cancer; ERK, extracellular signal regulated protein kinase; FBS, foetal bovine serum; GS, Gleason scoring; H3Thr11, histone $\mathrm{H} 3$ threonine 11; HEK, human embryonic kidney; HGPIN, high-grade prostatic intraepithelial neoplasia; IHC, immunohistochemistry; NSAID, non-steroidal antiinflammatory drug; PCa, prostate cancer; PIA, prostatic inflammatory atrophy; PK, protein kinase; PRK, protein kinase C-related kinase; Prm, promoter; PSA, prostatespecific antigen; PTS, pathological tumour staging; TMA, tumour microarray; TP, T prostanoid receptor; $\mathrm{TXA}_{2}$, thromboxane (TX) A ; WT1, Wilms' tumour (WT) 1.

\section{ACKNOWLEDGMENTS}

We would also like to thank Drs Helen Reid, Gillian O’Hurley, Amanda O’Neill and Agnieszka Krzyzanowska for their advice during the scoring and analysis of the TMA datasets.

\section{CONFLICTS OF INTEREST}

The authors declare that they have no competing interests.

\section{GRANT SUPPORT}

This work was supported by grants from the Irish Cancer Society, co-funded by the Health Research Board (Ireland) and the Movember Foundation (Grant no. PCI12KIN (MRCG/2012/3)), and the Programme for Research in Third Level Institutions (PRTLI; MolCellBiol) and the European Regional Development Fund. The "PCRC TMA" was funded by the Irish Cancer Society (PCI11WAT) as part of the Prostate Cancer Research Consortium (PCRC) and the Dublin Centre for Clinical Research, co-funded by the Wellcome Trust and Health Research Board.

\section{REFERENCES}

1. Attard G, Parker C, Eeles RA, Schroder F, Tomlins SA, Tannock I, Drake CG, de Bono JS. Prostate cancer. Lancet. 2016; 387:70-82.

2. Loeb S, Bruinsma SM, Nicholson J, Briganti A, Pickles T, Kakehi Y, Carlsson SV, Roobol MJ. Active surveillance for prostate cancer: a systematic review of clinicopathologic variables and biomarkers for risk stratification. Eur Urol. 2015; 67:619-26.

3. Paller CJ, Antonarakis ES, Eisenberger MA, Carducci MA. Management of patients with biochemical recurrence after local therapy for prostate cancer. Hematol Oncol Clin North Am. 2013; 27:1205-19, viii.

4. Karantanos T, Corn PG, Thompson TC. Prostate cancer progression after androgen deprivation therapy: mechanisms of castrate resistance and novel therapeutic approaches. Oncogene. 2013; 32:5501-11.

5. Rothwell PM, Fowkes FG, Belch JF, Ogawa H, Warlow CP, Meade TW. Effect of daily aspirin on long-term risk of death due to cancer: analysis of individual patient data from randomised trials. Lancet. 2011; 377:31-41.

6. Rothwell PM, Price JF, Fowkes FG, Zanchetti A, Roncaglioni MC, Tognoni G, Lee R, Belch JF, Wilson M, Mehta Z, Meade TW. Short-term effects of daily aspirin on cancer incidence, mortality, and non-vascular death: analysis of the time course of risks and benefits in 51 randomised controlled trials. Lancet. 2012; 379:1602-12.

7. Zha S, Yegnasubramanian V, Nelson WG, Isaacs WB, De Marzo AM. Cyclooxygenases in cancer: progress and perspective. Cancer Lett. 2004; 215:1-20.

8. Ekambaram P, Lambiv W, Cazzolli R, Ashton AW, Honn KV. The thromboxane synthase and receptor signaling pathway in cancer: an emerging paradigm in cancer progression and metastasis. Cancer Metastasis Rev. 2011; 30:397-408.

9. Miggin SM, Kinsella BT. Regulation of extracellular signalregulated kinase cascades by alpha- and beta-isoforms of the human thromboxane $\mathrm{A}(2)$ receptor. Mol Pharmacol. 2002; 61:817-31.

10. Wikstrom K, Kavanagh DJ, Reid HM, Kinsella BT. Differential regulation of RhoA-mediated signaling by the TPalpha and TPbeta isoforms of the human thromboxane A2 receptor: independent modulation of TPalpha signaling by prostacyclin and nitric oxide. Cell Signal. 2008; 20:1497-512.

11. Moussa O, Ashton AW, Fraig M, Garrett-Mayer E, Ghoneim MA, Halushka PV, Watson DK. Novel role of 
thromboxane receptors beta isoform in bladder cancer pathogenesis. Cancer Res. 2008; 68:4097-104.

12. Dassesse T, de Leval X, de Leval L, Pirotte B, Castronovo V, Waltregny D. Activation of the thromboxane A2 pathway in human prostate cancer correlates with tumor Gleason score and pathologic stage. Eur Urol. 2006; 50:1021-31; discussion 31.

13. Nie D, Che M, Zacharek A, Qiao Y, Li L, Li X, Lamberti M, Tang K, Cai Y, Guo Y, Grignon D, Honn KV. Differential expression of thromboxane synthase in prostate carcinoma: role in tumor cell motility. Am J Pathol. 2004; 164:429-39.

14. Gustafsson A, Hansson E, Kressner U, Nordgren S, Andersson M, Lonnroth C, Lundholm K. Prostanoid receptor expression in colorectal cancer related to tumor stage, differentiation and progression. Acta Oncol. 2007; 46:1107-12.

15. Sakai H, Suzuki T, Takahashi Y, Ukai M, Tauchi K, Fujii T, Horikawa N, Minamimura T, Tabuchi Y, Morii M, Tsukada K, Takeguchi N. Upregulation of thromboxane synthase in human colorectal carcinoma and the cancer cell proliferation by thromboxane A2. FEBS Lett. 2006; 580:3368-74.

16. Cathcart MC, Gately K, Cummins R, Kay E, O’Byrne KJ, Pidgeon GP. Examination of thromboxane synthase as a prognostic factor and therapeutic target in non-small cell lung cancer. Mol Cancer. 2011; 10:25.

17. Ho-Tin-Noe B, Goerge T, Wagner DD. Platelets: guardians of tumor vasculature. Cancer Res. 2009; 69:5623-6.

18. Kinsella BT. Thromboxane A2 signalling in humans: a 'Tail' of two receptors. Biochem Soc Trans. 2001; 29:641-54.

19. Turner EC, Kavanagh DJ, Mulvaney EP, McLean C, Wikstrom K, Reid HM, Kinsella BT. Identification of an interaction between the TPalpha and TPbeta isoforms of the human thromboxane A2 receptor with protein kinase C-related kinase (PRK) 1: implications for prostate cancer. J Biol Chem. 2011; 286:15440-57.

20. Reid HM, Wikstrom K, Kavanagh DJ, Mulvaney EP, Kinsella BT. Interaction of angio-associated migratory cell protein with the TPalpha and TPbeta isoforms of the human thromboxane A(2) receptor. Cell Signal. 2011.

21. Reid HM, Kinsella BT. Palmitoylation of the TPbeta isoform of the human thromboxane $\mathrm{A}(2)$ receptor. Modulation of $\mathrm{G}$ protein: Effector coupling and modes of receptor internalization. Cell Signal. 2007; 19:1056-70.

22. Kelley-Hickie LP, O’Keeffe MB, Reid HM, Kinsella BT. Homologous desensitization of signalling by the alpha (alpha) isoform of the human thromboxane A2 receptor: a specific role for nitric oxide signalling. Biochim Biophys Acta. 2007; 1773:970-89.

23. Miyosawa K, Sasaki M, Ohkubo S, Nakahata N. Different pathways for activation of extracellular signal-regulated kinase through thromboxane A2 receptor isoforms. Biol Pharm Bull. 2006; 29:719-24.

24. Gannon AM, Kinsella BT. Regulation of the human thromboxane A2 receptor gene by Sp1, Egr1, NF-E2,
GATA-1, and Ets-1 in megakaryocytes. J Lipid Res. 2008; 49:2590-604.

25. Gannon AM, Turner EC, Reid HM, Kinsella BT. Regulated Expression of the alpha Isoform of the Human Thromboxane A(2) Receptor during Megakaryocyte Differentiation: A Coordinated Role for WT1, Egr1, and Sp1. J Mol Biol. 2009; 394:29-45.

26. Coyle AT, Miggin SM, Kinsella BT. Characterization of the $5^{\prime}$ untranslated region of alpha and beta isoforms of the human thromboxane A2 receptor (TP). Differential promoter utilization by the TP isoforms. Eur J Biochem. 2002; 269:4058-73.

27. Coyle AT, Kinsella BT. Characterization of promoter 3 of the human thromboxane A receptor gene. A functional AP-1 and octamer motif are required for basal promoter activity. FEBS J. 2005; 272:1036-53.

28. Nie D, Guo Y, Yang D, Tang Y, Chen Y, Wang MT, Zacharek A, Qiao Y, Che M, Honn KV. Thromboxane A2 receptors in prostate carcinoma: expression and its role in regulating cell motility via small GTPase Rho. Cancer Res. 2008; 68:115-21.

29. Hutchinson CL, Lowe PN, McLaughlin SH, Mott HR, Owen D. Differential binding of RhoA, RhoB, and RhoC to protein kinase C-related kinase (PRK) isoforms PRK1, PRK2, and PRK3: PRKs have the highest affinity for RhoB. Biochemistry. 2013; 52:7999-8011.

30. Lachmann S, Jevons A, De Rycker M, Casamassima A, Radtke S, Collazos A, Parker PJ. Regulatory domain selectivity in the cell-type specific PKN-dependence of cell migration. PLoS One. 2011; 6:e21732.

31. Leenders F, Mopert K, Schmiedeknecht A, Santel A, Czauderna F, Aleku M, et al. PKN3 is required for malignant prostate cell growth downstream of activated PI 3-kinase. EMBO J. 2004; 23:3303-13.

32. Metzger E, Imhof A, Patel D, Kahl P, Hoffmeyer K, Friedrichs N, Müller JM, Greschik H, Kirfel J, Ji S, Kunowska N, Beisenherz-Huss C, Günther T, et al. Phosphorylation of histone H3T6 by PKCbeta(I) controls demethylation at histone H3K4. Nature. 2010; 464:792-6.

33. Metzger E, Muller JM, Ferrari S, Buettner R, Schule R. A novel inducible transactivation domain in the androgen receptor: implications for PRK in prostate cancer. EMBO J. 2003; 22:270-80.

34. Metzger E, Yin N, Wissmann M, Kunowska N, Fischer K, Friedrichs N, Patnaik D, Higgins JM, Potier N, Scheidtmann KH, Buettner R, Schüle R. Phosphorylation of histone $\mathrm{H} 3$ at threonine 11 establishes a novel chromatin mark for transcriptional regulation. Nat Cell Biol. 2008; 10:53-60.

35. O'Sullivan AG, Mulvaney EP, Hyland PB, Kinsella BT. Protein kinase C-related kinase 1 and 2 play an essential role in thromboxane-mediated neoplastic responses in prostate cancer. Oncotarget. 2015; 6:26437-56. doi: 10.18632/oncotarget.4664. 
36. Miggin SM, Kinsella BT. Thromboxane A(2) receptor mediated activation of the mitogen activated protein kinase cascades in human uterine smooth muscle cells. Biochim Biophys Acta. 2001; 1539:147-62.

37. Iczkowski KA, Lucia MS. Current perspectives on Gleason grading of prostate cancer. Curr Urol Rep 2011;12:216-22.

38. Baylin SB. DNA methylation and gene silencing in cancer. Nat Clin Pract Oncol. 2005; 2:S4-11.

39. Cuzick J, Thorat MA, Bosetti C, Brown PH, Cook NR, Ford LG, Jacobs EJ, Jankowski JA, La Vecchia C, Law M, Meyskens F, Rothwell PM, Senn HJ, et al. Estimates of benefits and harms of prophylactic use of aspirin in the general population. Annals of Oncology. 2015; 26:47-57.

40. Rothwell PM, Wilson M, Price JF, Belch JF, Meade TW, Mehta Z. Effect of daily aspirin on risk of cancer metastasis: a study of incident cancers during randomised controlled trials. Lancet. 2012; 379:1591-601.

41. Moussa O, Ciupek A, Watson DK, Halushka PV. Urinary thromboxane $\mathrm{B}(2)$ and thromboxane receptors in bladder cancer: Opportunity for detection and monitoring. Prostaglandins Other Lipid Media. 2011; 96:41-4.

42. Kelley-Hickie LP, Kinsella BT. Homologous desensitization of signalling by the beta (beta) isoform of the human thromboxane A2 receptor. Biochim Biophys Acta. 2006; 1761:1114-31.

43. Kinsella BT. Transcriptional Regulation of the Human Thromboxane A2 Receptor Gene by Wilms' Tumour (WT)1. In: van den Heuvel-Eibrink MM, editor. Wilms Tumor. Brisbane (AU). 2016.

44. Walsh MT, Foley JF, Kinsella BT. The alpha, but not the beta, isoform of the human thromboxane A2 receptor is a target for prostacyclin-mediated desensitization. J Biol Chem. 2000; 275:20412-23.

45. Hirata T, Narumiya S. Prostanoids as regulators of innate and adaptive immunity. Adv Immunol. 2012; 116:143-74.

46. Kabashima K, Murata T, Tanaka H, Matsuoka T, Sakata D, Yoshida N, Katagiri K, Kinashi T, Tanaka T, Miyasaka M, Nagai H, Ushikubi F, Narumiya S. Thromboxane A2 modulates interaction of dendritic cells and $\mathrm{T}$ cells and regulates acquired immunity. Nat Immunol. 2003; 4:694-701.

47. Moalli F, Cupovic J, Thelen F, Halbherr P, Fukui Y, Narumiya S, Ludewig B, Stein JV. Thromboxane A2 acts as tonic immunoregulator by preferential disruption of lowavidity CD4+ T cell-dendritic cell interactions. J Exp Med. 2014; 211:2507-17.

48. Thomas DW, Rocha PN, Nataraj C, Robinson LA, Spurney RF, Koller BH, Coffman TM. Proinflammatory actions of thromboxane receptors to enhance cellular immune responses. J Immunol. 2003; 171:6389-95.

49. Yang CW, Unanue ER. Neutrophils control the magnitude and spread of the immune response in a thromboxane A2mediated process. J Exp Med. 2013; 210:375-87.

50. Yang Q, Shi M, Shen Y, Cao Y, Zuo S, Zuo C, Zhang H, Gabrilovich DI, Yu Y, Zhou J. COX-1-derived thromboxane A2 plays an essential role in early B-cell development via regulation of JAK/STAT5 signaling in mouse. Blood. 2014; 124:1610-21.

51. Strittmatter F, Gratzke C, Weinhold P, Steib CJ, Hartmann AC, Schlenker B, Andersson KE, Hedlund P, Stief CG, Hennenberg M. Thromboxane A2 induces contraction of human prostate smooth muscle by Rho kinase- and calmodulin-dependent mechanisms. Eur J Pharmacol.2011; 650:650-5.

52. Walsh M, Foley JF, Kinsella BT. Investigation of the role of the carboxyl-terminal tails of the alpha and beta isoforms of the human thromboxane $\mathrm{A}(2)$ receptor (TP) in mediating receptor:effector coupling. Biochim Biophys Acta. 2000; 1496:164-82.

53. Valentin F, Field MC, Tippins JR. The mechanism of oxidative stress stabilization of the thromboxane receptor in COS-7 cells. J Biol Chem. 2004; 279:8316-24.

54. Theriault C, Rochdi MD, Parent JL. Role of the Rab11associated intracellular pool of receptors formed by constitutive endocytosis of the beta isoform of the thromboxane A2 receptor (TP beta). Biochemistry. 2004; 43:5600-7.

55. Jahn JL, Giovannucci EL, Stampfer MJ. The high prevalence of undiagnosed prostate cancer at autopsy: implications for epidemiology and treatment of prostate cancer in the Prostate-specific Antigen-era. Int J Cancer. 2015; 137:2795-802.

56. Smith ZD, Meissner A. DNA methylation: roles in mammalian development. Nat Rev Genet. 2013; 14:204-20.

57. Keating GL, Reid HM, Eivers SB, Mulvaney EP, Kinsella BT. Transcriptional regulation of the human thromboxane A2 receptor gene by Wilms' tumor (WT)1 and hypermethylated in cancer (HIC) 1 in prostate and breast cancers. Biochim Biophys Acta. 2014; 1839:476-92.

58. Livak KJ, Schmittgen TD. Analysis of relative gene expression data using real-time quantitative PCR and the 2(-Delta Delta C(T)) Method. Methods. 2001; 25:402-8.

59. Assenov Y, Muller F, Lutsik P, Walter J, Lengauer T, Bock C. Comprehensive analysis of DNA methylation data with RnBeads. Nat Methods. 2014; 11:1138-40. 